\title{
How does grit impact college students' academic achievement in science?
}

\author{
Paul Bazelais ${ }^{1, *}$, David John Lemay ${ }^{1}$ and Tenzin Doleck ${ }^{1}$ \\ ${ }^{1}$ McGill University, Montréal , Canada \\ For correspondence: paul.bazelais@mail.mcgill.ca
}

\begin{abstract}
Research has suggested that achievement is not solely based on the cognitive abilities of the learner, but rather on the combination of cognitive ability and personality traits. This paper explores how grit affects student academic performance and success in first-year college physics students in the context of a Quebec Collège d'enseignement général et professionnel (CEGEP). Two hierarchical linear regressions were performed using scores on a 12-item 5point Likert scale survey measure of Grit on student cumulative GPA and on final exam mark for a gateway physics course, controlling for gender and high school GPA. Prior academic performance was found to be a significant predictor of college performance, as well as success in the gateway physics course. Grit was not found to be a significant predictor of student academic achievement or course success.
\end{abstract}

Keywords: Grit, Academic Achievement, Perseverance, Physics Performance, STEM Learning, CEGEP, Gender Differences, Introductory Physics.

\section{Introduction}

The importance of science, technology, engineering, and mathematics (STEM) has been widely acknowledged in a significant body of writing in both the educational literature and the media because of its important role in shaping the workforce of the future. However, the stubbornly high attrition rate in STEM majors remains a pressing problem (Chen, 2013) that affects the pipeline of graduates in STEM and consequently the technical labor force. Struggling to complete introductory STEM courses can result in loss of confidence and motivation, eventually leading to a shift away from STEM majors (Gasiewski, Eagan, Garcia, Hurtado, \& Chang, 2011). In an intuitive sense, we tend to attribute to individuals the quality of perseverance in determining who drops out and who is persistent enough to stay the course. Thus, investigations of dispositions that affect student persistence and achievement outcomes are increasingly receiving attention.

Intellectual ability is widely considered to predict academic achievement (Poropat, 2009). Duckworth, Peterson, Matthews, \& Kelly (2007) note that the link between intellectual ability and achievement has been well established. However, intellectual ability is no guarantor of success in completing college programs or later in life. Some, such as Duckworth et al. (2007) have argued that these achievement differences could be explained by personality variables such as trait-like perseverance, or what they term 'grit'; but the influence of these other individual differences or traits on achievement is unclear. While the focus on intellectual ability on academic achievement has been understandable and even necessary, there is a growing awareness of the inadequacy of intellectual ability to predict all facets of academic achievement and success later in life. Thus, researchers have begun incorporating other motivational and personality variables in order to explain academic achievement differences. Personality variables such as grit could help shed light on academic success and, consequently, STEM attrition. 
Duckworth, et al. (2007) define grit as "perseverance and passion for long-term goals" and state that grit "entails working strenuously toward challenges, maintaining effort and interest over years despite failure, adversity, and plateaus in progress" (p.1087). Grit may be an important factor in explaining achievement and persistence (Bowman, Hill, Denson \& Bronkema, 2015; Strayhorn, 2013). The Grit Scale and the Short Grit Scale are multiple-item self-report scales developed and validated by Duckworth and colleagues (Peterson, Matthews, \& Kelly, 2007; Duckworth \& Quinn, 2009) and contain questions geared toward eliciting perceptions about behaviors related to setting and pursuing achievement goals (e.g., "I have overcome setbacks to conquer an important challenge", "I become interested in new pursuits every few months", and "I am diligent").

Past academic performance has been used both as a proxy for student persistence (Cabrera, Nora, Terenzini, Pascarella \& Hagedorn, 1999; Ishitani \& DesJardins, 2002) and for cognitive ability. Measures like high school GPA have been widely used for predicting academic achievement (Komarraju, Ramsey, \& Rinella, 2013). But past academic performance are retrospective indicators and say nothing about prospective behaviors. Measures that can probe traits rather than states ought to be better indicators of personality differences, such as trait-like perservance or grit. Training the investigative lens on personality differences might reveal new insights on the link between such traits and success and/or persistence, and help researchers and practitioners better understand why high ability students drop out of STEM majors or why students of lesser ability sometimes perform better.

Although many studies have examined the role of the construct of grit in success, there have been no studies heretofore that have examined the influence of grit on the academic achievement of Collège d'enseignement général et professionnel (CEGEP) students. The CEGEP system is a unique postsecondary education system in the province of Quebec in Canada, and is similar to the US community college system. Investigating grit's predictive power in the academic achievement of CEGEP students is important for a number of reasons. First, CEGEP's serve as a gateway for students in Quebec planning on entering a Quebec university. Second, the percentage of students completing the twoyear pre-university program within the two-year period is stubbornly low $(<60 \%)$. It should be noted that a majority of studies investigating the construct of grit have focused on populations identified as high-achievers, gifted, and or talented. This article represents a first step toward achieving our aim to test the predictive capacity of grit in the context of a more general ability-level, college-age population. This study uses a subsample of CEGEP science students to examine the relationships between grit and achievement. For our present study we operationalize achievement at both the macro (CEGEP GPA) and micro (Physics course grade) level. Furthermore, we also examine if there are gender differences in grit scores in this specific population since gender differences have been observed in college science students (Jaeger, Freeman, Whalen, \& Payne, 2010).

The present study was conducted at John Abbott College, a CEGEP located in the West Island area of Montreal, Quebec. CEGEPs are post-secondary institutions that offer general education at the preuniversity level and act as an intermediary between secondary school and university. In Quebec, students intending to enroll in a Quebec university must pass through the CEGEP system and obtain a Diploma of College Studies (DEC; Diplôme d'études collégiales). Along with serving as a springboard for university studies, CEGEPs also prepare students studying a trade or profession for the workforce via three-year technical programs leading to an Attestation of College Studies (AEC; Attestation d'études collégiales; Rocher, 2008). The CEGEP system is composed of a mix of both public and private and English and French colleges.

Electricity \& Magnetism (E\&M; Physics NYB) is the second of three required physics courses that preuniversity science students must take at John Abbott College. Electromagnetism is the most challenging and content driven physics course at the CEGEP level and it is also associated with the lowest success rate of the three required physics courses in the department. In 2013 , less than $80 \%$ of the original cohort of 530 students continued into the $2^{\text {nd }}$ year of the program after taking the E\&M course. One reason for the low success rate and retention may be the abstract nature of the E\&M concepts for many students. Whereas the concepts of Newtonian physics can be very intuitive and coherent for many students since they tend to build on real-world experiences, the concepts of E\&M such as electrostatic, moving charges, electric and magnetic fields phenomena, and circuit networks, 
have no real world analog. These concepts tend to be hard to conceptualize and may even appear counter-intuitive to many students. Another possible reason for the low success rate and high attrition in these courses may be presence or absence of certain personality traits within the student population. This study aims to analyze the impacts of trait-like perseverance or grit on academic performance of CEGEP science students.

The rest of this paper is organized as follows. Section 2 discusses the literature. Section 3 outlines the methods. Section 4 presents the results. Finally, Section 5 concludes the paper with a discussion of the study's results, its limitations, and future directions for research.

\section{Grit and Academic Performance}

Prior research has confirmed that grades and intelligence are the most reliable measure of student persistence in college and universities (Duckworth et al., 2007; Gottfredson, 1997; Hartigan \& Wigdor, 1989; Pascarella \& Terenzini, 2005). However, there is ample research that demonstrates that abilities such as talent, intelligence, and IQ are not significant predictors of high achievement or later success (De Vera, Gavino, \& Portugal, 2015; Duckworth et al., 2007; Duckworth \& Seligman, 2005; Dweck, 2007). Current research posits that trait-like perseverance is related to better performance and greater success in both academia and in the real-world setting (De Vera et al., 2015; Duckworth et al. 2007; Ivcevic \& Brackett, 2014). If students with less academic ability can perform equally well compared to students with more academic ability then perhaps there exists other more reliable measures of academic achievement or persistence in colleges.

Duckworth et al. (2007) argue that achievement results from a combination of innate talent and effort. In other words, success is not solely based on the learner's abilities but rather on the combination of cognitive ability and personality traits, such as grit, as well as deliberate practice. Hogan \& Wong (2013) argue that grittier individuals tend to work harder and longer and are more inclined to engage in deliberate practice to enhance performance or success. Performances are limited by innate factors and cognitive skills, and require deliberate efforts on the part of the individual to change or improve particular characteristics of performance (Ericsson, 2006; Duckworth et al., 2011). Grittier individuals are more persistent and diligent, not discouraged by setbacks or failure, more focused on a project or goal, and more likely to complete tasks. In contrast, less gritty individuals aren't as persistent or diligent, they are easily distracted by new ideas or projects, unable to set long-term goals, and lack motivation or focus for long-term projects. However, despite these findings there is a lack of research on the role played by personality traits such as grittiness on the academic achievement or the later success of the learner.

Current research tends to support the contention that grit is as important as grades and IQ for high academic achievement and success (Duckworth et al., 2007). Grit-quality trait perseverance, more than grades and IQ or conscientiousness, may even be responsible for explaining differences in the ranks of high achieving and performing individuals. Duckworth et al. (2007) collected self-reporting grit-scale data, as well as age and level of education from $(n=1,545)$ participants, aged 25 and older $(\mathrm{M}=45$ years; $73 \%$ women, $27 \%$ men) through a noncommercial public website. A two-way analysis was used to predict the variance in grit by education and age, while treating age and education as categorical variables. Their study revealed that more educated adults had higher grit than less educated adults of similar age. In addition, a post-hoc analysis showed that when age is controlled for, post-college graduates had higher grit than most other groups. Furthermore, their finding showed that when education is controlled for, grit increases with age. They reasoned that older adults have more life experience, perseverance or passion for long-term goals, and that persistence and diligence are key strategies for longtime success, though their study was limited due the crosssectional design in nature, which limited their capacity to make strong causal inferences between grit and age.

Duckworth et al. (2007) also studied $(n=139)$ grit and academic achievement in a population of elite undergraduate psychology students $(69 \%$ women, $31 \%$ men) from an Ivy League University in the United States. Their combined average SAT score was 1,415 - a score attained by less than $4 \%$ of 
students who take the SAT. The authors found that grittier students got better results than less gritty students, that is, grit scores were associated with high GPA, $r=.25, p<.01$. SAT scores were also strongly correlated with GPA, $r=.30, p<.001$ but their study revealed that grit was related with lower SAT scores $r=-.20, p<.03$ (suggesting that smarter or more gifted students may be a bit less gritty than their peers. A finding that was previously confirmed by Moutafi et al. (2005), who studied a diverse sample of job applicants and showed that conscientiousness and general intelligence were negatively correlated, $r=.25, p<.01$. It is plausible, as Moutafi et al. (2005) have proposed that among quite intelligent individuals, those who are presumably less gifted than their peers compensate by working harder and with more self-determination and drive.

Duckworth et al. (2007), report on a third study of grit among first year cadets ( $n=1,218 ; 84 \%$ men, $16 \%$ women) who attended the elite United States Military Academy at West Point, in July 2004. They conducted a binary logistic regression analysis with retention as DV, in order to determine the effects of grit, self-control, and the whole candidate score, the criterion used by West Point to admit cadets. The results showed that grit was a better predictor of completion rates for the rigorous summer program than self-control or the whole candidate score. The results showed that grit was highly related to self-control, $r=.63, p<.001$, yet results demonstrated that grittier cadets were more than $60 \%$ likelier to remain at the end of the program $(\beta=.48, p<.001)$, whereas, those with high levels of self-control were only $50 \%$ more likely to remain $(\beta=.48, p<.001)$. The whole candidate score did not significantly predict summer retention $(\beta=.09, n s)$. However, self-control was a better predictor of cumulative GPA $(r=.13, p<.001)$ and Military Performance Score $(r=.21, p<.001)$ than grit on cumulative GPA $(r=.06, p<.05)$ and Military Performance Score $(r=.19, p<.001)$. These results tend to show that perseverance of effort and self-control are key to retention and success in completing the first summer training program at West Point Academy.

Jaeger, Freeman, Whalen, \& Payne, (2010) studied the effects of grit in engineering students at Northeastern University. Their study was guided by two main questions: 1) Is grit associated to student characteristics such as gender, academic level, and SAT scores? 2) What is the effect of grit over time when grit scores of first year students are compared to upperclassmen? Interestingly, their results revealed significant gender differences in grit scores. There has been mixed results regarding group differences in grit scores. For instance, Rojas, Reser, Usher, \& Toland (2012) found that females reported higher grit than males, while Batres (2011) reported no gender differences in grit scores. In their study, Jaeger et al. (2010) found that female students were grittier than their male counterparts. However, grit did not appear to predict either academic level or SAT score. Grit scores were further discretized by student's concentration or major within the engineering program, for example, honor and non-honor students, athletes and non-athletes students, etc. The results revealed that Chemical and Mechanical Engineering students were the grittiest, whereas Computer Engineering students were the least. No significance difference was found in grit among honor and non-honor engineering students and athlete or non-athlete engineering students though the study did show that non-honors and athlete engineering students were grittier than honors and non-athlete engineering students. Jaeger et al. (2010) conclude that more research on grit is needed in order to better understand the effect of grit on academic performance or student success.

Chang (2014) studied the effects of grit on race, gender, and academic performance of a diverse population of $(n=342,67 \%$ female, $33 \%$ male) first year college students from a highly selective private four-year college located in the Southern United States. The sample was drawn from $(\mathrm{N}=2035,51 \%$ female, $49 \%$ male) incoming first year students for the 2013 academic year. $72 \%$ of incoming students ranked in the top $10 \%$ of their high school class, with $51 \%$ ranked in the top $5 \%$. Of the incoming first year students, 55\% were white, 9\% black, 18\% Hispanic, and 14\% Asian/Pacific islander. The data consisted of previous academic achievement (ACT/SAT scores and HSGPA), grit survey data, and academic performance, namely first year cumulative GPA. All incoming first year students were invited to take the grit scale survey through an online survey during the two weeks period the survey was open to the students. Chang (2014) conducted a hierarchical multiple regression analysis in order to determine the effects of grit, gender, race and previous academic achievement (IVs) on academic performance (DV). The results showed that grit was not a significant predictor of first year GPA, $\beta=.07, p<.19$. No significant differences were observed for any of the 
racial groups, indicating no differences in first year GPA by race. However, the results showed first year GPA differed by gender $(\beta=.14, p<.05)$, indicating that females on average had significantly higher first year GPA. Furthermore, Chang (2014) analyzed whether the grit subscales, consistency of interest and perseverance of effort, were significant predictors of academic performance in first year college students. The results showed that the perseverance subscales was a positive and significant predictor of first year GPA, $\beta=.22, p<.01$, while controlling for the interest subscale, indicating that a one standard deviation increase in perseverance subscale would increase first year GPA by 22 . Whereas, the interest subscale resulted in a negative and significant predictor of first GPA, $\beta=-.11$ $p<.01$, indicating that a one standard deviation increase of the interest subscale score would decrease the first year GPA by .11. The interaction between the two grit subscales was not significant in predicting first year GPA.

De Vera et al. (2015) conducted a qualitative study of management students ( $n=25)$ in an Asian graduate school to investigate the factors contributing to grit in a non-western context. The data collected consisted of in-depth interviews from a diverse population (different ages and nationalities) of randomly selected graduate management students in an Asian graduate school. De Vera et al. found that social support was a crucial element to passion and perseverance in achieving personal and work goals. Participants wrote that "grit is long-term" and "emphasizes steadfastness and perseverance" (De Vera et al., 2015, p.3). The authors posited that grit was related to "the ability to continue, commitment to growth, consistency, determination, drive to succeed, firmness, passion to excel, and personal commitment" (De Vera et al., 2015, p.3). Participants reported that both inner and personal strength forced them to perform better in order to make up for a lack of talent or inherent ability. Consistent with Duckworth et al. (2007), the findings suggest that intelligence and IQ are not significant predictors of success. The participants further argued that grit was associated with persistence, and the strong reliance on external or social support systems (such as family, friends, significant others, superiors and co-workers), and as well as internal factors of motivation (such as intrinsic motivation, self-efficacy, and self-regulation). De Vera et al. (2015) also investigated grit and work performance of medical sales representatives $(n=408)$ of a global pharmaceutical company in the Philippines. To investigate the effect of grit and work performance, the researchers conducted a bi-variate analysis of grit and comparison measures targeted by the pharmaceutical company, which included performance metrics such as appointment based-calls, call concentration, call rate performance, FCT days, HCP reach, and sales performance based on existing company records. Respondents who scored high on these metrics were considered as "high performers" and were perceived as highly motivated individuals working in an extremely demanding and competitive work environment. These individuals had high motivation, self-efficacy and regulation. Results showed that there were no significant association between high performance and grit. De Vera et al. (2015) argue that sales representative performance may not be associated with long-term quality trait of grit and that their performance depends on more immediate success or reward.

\section{Method}

The purpose of this study was to examine whether grit is associated with academic performance in pre-university science college students. The primary measure was the grit score, as measured by the 12-item, 5-point Likert-style Grit Scale Survey (Duckworth et al., 2007). Controlling for academic ability using cumulative GPA and R-score, we examined whether grit could significantly predict the variance in academic performance using final exam marks for E\&M course.

Participants were $(n=156)$ first year, second semester pre-university science students ( $53 \%$ male, $47 \%$ female) at John Abbott College, a CEGEP in Montreal. Participants were recruited from five sections of the Electricity \& Magnetism course. Student participation was voluntary. Participants of this study had to be 18 years old to consent to be part of the research. Participants gave written informed consent and were given the choice to withdraw or not submit their data. The participants were informed of the confidential nature of the study and the data and were informed that study results would not be linked to any student's name or student ID number. An anonymous coding scheme was used to ensure confidentiality. 
In order to rule out systematic bias, we present comparative statistics on our sample and the 20142015 Physics NYB cohort. We found no systematic difference between our sample and the cohort. The E\&M course average for our sample of 156 students was $72.27 \%$ while the E\&M course average for the rest of the cohort (excluding the sample) was $69.81 \%$. The average GPA for the sample was $83.65 \%$, while the GPA for the remainder of the cohort was $82.23 \%$.

For Winter 2015, a total of 477 students were registered for E\&M but only 468 took the final exam. The E\&M final exam average was 69.81 including Honors (sections 1 and 2, a total of 39 honors students). However, note that no Honors student took the grit survey. The overall average excluding Honors was 68.53. A total of 80 students failed the course, but no Honors student failed. Excluding the Honors group $(468-39=429)$, the exam pass-rate for Winter 2015 was $(429-80) / 429$, or about $81 \%$.

Research Questions.

This study was guided by the following research questions:

1. What is the effect of grit on CEGEP academic performance for pre-university college science students?

2. What is the effect of grit on final exam performance in a pre-university college E\&M physics course?

3. Is there a significant difference in grit scores between males and females?

\section{Results}

Research Question 1.

To answer question 1, a hierarchical multiple linear regression was performed to test for the effects of grit scores on CEGEP academic performance, while controlling for gender and high school GPA. Prior to conducting the hierarchical multiple regression, the relevant tests of assumptions of linearity, normality, and homoscedasticity were performed and no violations were observed. In addition, both the Tolerance and VIF values indicate that there is no multicollinearity.

Table 1. Correlations

\begin{tabular}{llrrrr}
\hline & & CEGEP GPA & Gender & H.S. GPA & Grit \\
\hline Pearson Correlation & CEGEP GPA & 1.000 & -.055 & $.661^{* *}$ & .108 \\
& Gender & -.055 & 1.000 & $-.141^{*}$ & $-.140^{*}$ \\
& H. S. GPA & $.661^{* *}$ & $-.141^{*}$ & 1.000 & .078 \\
& Grit & .108 & $-.140^{*}$ & .078 & 1.000 \\
\hline
\end{tabular}

${ }^{* *} p<.01,{ }^{*} p<.05$

Gender and high school GPA were entered first into the model (controlling variables), followed with the IV of interest (grit scores) was entered with academic performance (CEGEP GPA) as the DV. The first block of IV (gender and high school GPA) explained approximately $43.8 \%$ of the variance in academic performance $\left(R^{2}=.438\right)$ and was found to be significant, $F(2,149)=58.18, p<0.001$. When the grit score was included in the second block, the model as a whole explained approximately $44.2 \%$ of the variance in academic performance $\left(R^{2}=.442\right)$ as displayed in Table 2 . The results revealed that grit was not a significant predictor of academic performance $\left(R^{2}\right.$ change $=.004$; $F$ change $(1,148)=$ $1.043, p=.309)$. Whereas, the overall model was found to be significant, $F(3,148)=39.145, p<0.001$.

Moreover, from the three IVs, only high school GPA was a significant predictor of academic performance. A one-point change in high school GPA was related to a .420 increase in academic performance as indicated in Table 3. 
Table 2. Model Summary

\begin{tabular}{lrrrrrrrrrr}
\hline & \multicolumn{9}{c}{$\begin{array}{c}c \\
\text { Std. Error } \\
\text { of the }\end{array}$} & \multicolumn{4}{c}{ Change Statistics } \\
Model & $R$ & $R^{2}$ & $R^{2}$ & Estimate & $R^{2}$ Change & Change & $d f_{1}$ & $d f_{2}$ & Change \\
\hline 1 & $.662^{\mathrm{a}}$ & .438 & .431 & 2.63821 & .438 & 58.180 & 2 & 149 & .000 \\
2 & $.665^{\mathrm{b}}$ & .442 & .431 & 2.63782 & .004 & 1.043 & 1 & 148 & .309 \\
\hline
\end{tabular}

a. Predictors: (Constant), H.S. GPA, Gender

b. Predictors: (Constant), H.S. GPA, Gender, Grit

Table 3. Hierarchical Multiple Regression Analysis of Grit on Academic Performance while controlling for Gender and High School GPA

\begin{tabular}{lrrrr}
\hline & $B$ & SE-b & $T$ & Beta \\
\hline Gender & .329 & .437 & .753 & .047 \\
H.S. GPA & .420 & .039 & 10.672 & $.663^{*}$ \\
Grit & .415 & .406 & 1.021 & .063 \\
\hline
\end{tabular}

$* p<.05$

Research Question 2.

To answer question 2, a hierarchical multiple linear regression was conducted in order to test for the effects of grit scores on physics performance, while controlling for gender and high school GPA. Tests of assumptions were performed, and all the assumptions were met in this data set, including assumptions of linearity, normality, and homoscedasticity. No violations were observed.

Table 4. Correlations

\begin{tabular}{|c|c|c|c|c|c|}
\hline \multicolumn{6}{|c|}{ Final Exam } \\
\hline & & Score & Gender & H.S. GPA & Grit \\
\hline \multirow[t]{4}{*}{ Pearson Correlation } & Final Exam Score & 1.000 & $.199^{* *}$ & $.272^{* *}$ & .060 \\
\hline & Gender & $.199^{* *}$ & 1.000 & $-.141^{*}$ & -.140 \\
\hline & H.S. GPA & $.272^{* *}$ & $-.141^{*}$ & 1.000 & $.078^{*}$ \\
\hline & Grit & .060 & $-.110^{*}$ & .078 & 1.000 \\
\hline
\end{tabular}

Gender and High School GPA were entered first into the model (controlling variables), followed by Grit as IV and Final Exam Score as the DV. The first block (Gender and H.S. GPA) explained approximately $13.1 \%$ of the variance in academic performance $\left(R^{2}=.131\right)$. These results were found to be significant, $F(2,149)=11.241, p<.001$ as indicated in Table 3. When Grit was included in the second block, the model as a whole explained approximately $13.6 \%$ of the variance in physics performance $\left(R^{2}=.136\right)$. As displayed in Table 7 , grit was not a significant predictor of physics performance $\left(R^{2}\right.$ change $=.005 ; F$ change $\left.(1,148)=.865, p=.354\right)$. Whereas, the overall model was found to be significant, $F(3,148)=7.775, p<0.001$.

Of the three IVs, only Gender and High School GPA were found to be significant predictors of academic performance as indicated in Table 6. A one-point change in high school GPA was related to a .937 increase in academic performance. 
Table 5. Model Summary

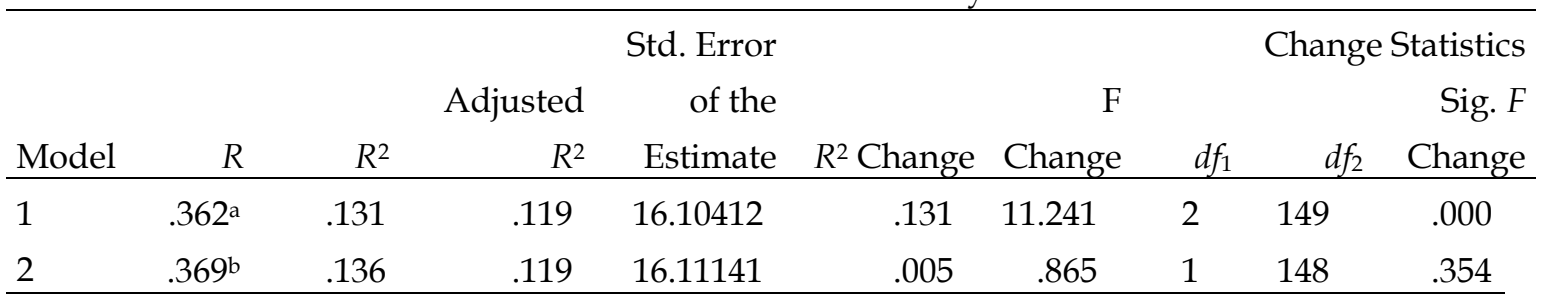

a. Predictors: (Constant), H.S. GPA, Gender

b. Predictors: (Constant), H.S. GPA, Gender, Grit

Table 6. Hierarchical Multiple Regression Analysis of Grit on Academic Performance while controlling for Gender and High School GPA

\begin{tabular}{lrrrr}
\hline & $B$ & $S E-b$ & $t$ & Beta \\
\hline Gender & 8.607 & 2.669 & 3.225 & $.251^{*}$ \\
HS GPA & .937 & .240 & 3.902 & $.302^{*}$ \\
Grit & 2.308 & 2.481 & .930 & .072 \\
\hline$* p<.05$ & & &
\end{tabular}

Research Question 3.

In order to answer question 3, an independent t-test was conducted to examine whether there were significant gender differences in grit scores. The results of test are presented in Table 9 . The analysis failed to reveal a significant difference between the two groups, $t(154)=1.630, p=.105$. The sample means show that females had grit scores which were quite similar to males (for females, $M=3.4967$, $S D=.53769$; for males, $\mathrm{M}=3.3576, S D=.52651)$.

\section{Discussion}

There was no significant relationship found between grit and student achievement in a gateway college physics course. Grit provided no incremental predictive validity over past student achievement as measured by high school GPA.

In previous studies, grit only explained a very small amount of total variance explained when age, SAT scores, and/or GPA were accounted for (Duckworth et al., 2007) or did not significantly predict student achievement (Chang, 2014; Jaeger et al., 2010). Further, Duckworth et al. found that grit varied with age. Therefore, it is likely that grit doesn't provide enough discriminant power among younger students, perhaps because their interests are not stable yet and the benefits of persistent effort had not yet made themselves readily apparent. From an evolutionary perspective, novelty seeking behavior can be considered adaptive among young adults, who are many still trying to discover what they are good at and what they enjoy doing. Hence, grit may have better postdictive power especially among older populations.

The conjectured greater postdictive power of grit raises the issue of social desirability. The advantages of consistent interests and persistent efforts are not necessarily clear to younger populations, at least not in the same way as for older ones who can point to examples of successful people who 'stuck to it in the face of insurmountable odds'. However, while not only being susceptible to social desirability bias, grit as it described here may also suffer from the halo effect or even the availability bias (Tversky \& Kahneman, 1974). It is indeed very easy to point to examples of entrepreneurs who overcame important obstacles and early failures to come to know great success. Yet, for every successful business there are hundreds of failures. And not every success is on the order of Elon Musk. In other words, it is simply untrue that persistent effort is always and necessarily adaptive in every situation. In fact, sometimes the best strategy is to walk away and try something different. In fact, real 
'grittiness' is being able to get up even when you've failed; it's knowing when to admit defeat and always being ready to try something new. Triumphing over adversity doesn't mean beating your head against the wall when the game is already lost. This speaks to the contingent nature of achievement in a spectrum of human pursuits, where success is not just a matter of ability and effort, but also a host of situational factors that frame individual action. It speaks to a very different kind of grittiness than that exhibited by high performing individuals who expend tremendous effort in deliberate practice in a fairly constrained activity context. Even in the relatively transparent context of academic achievement, where performance measures abound, it is not immediately obvious that all students stand on equal footing or that they face the same challenges and obstacles to success, differences in level of perseverance or expenditure of effort notwithstanding. As noted by the participants interviewed by De Vera et al. (2015), grit also depends on your social support network.

Whereas grit appears to evolve over time (Duckworth, et al., 2007, p.1092), there is a similar construct, work ethic, which seems to be a trait that is set early (Meriac, 2015). Work ethic appears to be a stable individual difference across cultural groups and genders. Meriac (2015) argues that the negative correlation between hard work and GPA can be accounted by the fact that students may be "working harder, but not working smarter (p.533)". The absence of a relationship between grit and GPA for military officers and of mediation of study hours for spelling bee contestants in Duckworth et al (2007) may also result from the fact that persistence of effort says nothing about the quality of the exertion. Also, as noted by Chang (2014), the dimensions of consistency of interest and persistence of effort may be at odds with each other. At the college-level, it becomes salient for students to ask themselves whether the incremental benefit of the expenditure of increased effort is the best course of action, when extra effort does not always entail greater success - especially in the short time frames of an individual course at the outset of one's academic career.

In a mixed, multi-dimensional regression study of motivation and self-regulation effects on dropping out of high school, only perseverance of effort dimension and not consistency of interests dimension of the GRIT-S scale distinguished between anticipated school outcomes (Meyers, Pignault, \& Houssemand, 2013). There were significant intercorrelatations between most measures. Persistence of effort was highly correlated, yet consistency of interests was not significantly correlated with other measures of motivation, to the exception of a negative correlation with amotivation. Consistency of interests is not necessarily adaptive in all situations and for all age groups. Novelty seeking is an important albeit risky pursuit for young people, but sticking to an out-dated and dying field of work is not always a good professional strategy either. Studying grit in relatively constrained fields or disciplines as opposed to more generalized achievement contexts such as high school or college may be confounding participants' preexisting interest for their chosen field with retrospective selfevaluations of the consistency of their interests over time. Echoing Duckworth et al. (2007), it is important to match the Grit Scale with other measures and with other populations, to further validate and generalize these findings.

Finally, cultural factors are important to consider above and beyond personal differences in achievement contexts (Galla, Plummer, White, Meketon, D'Mello, \& Duckworth, 2014; Pina-Watson, Lopez, Ojeda, \& Rodiguez, 2015). Clearly lower SES are not systematically less gritty than their peers, only that there are institutional biases that can impede equality of opportunity. Lower SES may face greater challenges than their peers and, as discussed above, changing tack can indeed be more adaptive in some situations. Focusing on individual differences at the expense of social-institutional factors runs the risk of biasing analyses from the very start and ignores the pernicious effects wrought by the systemic inequities which often plague our institutions.

Thus, the absence of any incremental predictive validity for grit over and above GPA can possibly be accounted for by population differences due to maturational variables and to the stability of the grit trait over time. Social desirability and availability bias, and cultural factors are also possible confounds. Persistence of effort and consistency of interests may not be the most salient factors in determining short-term achievement profiles in college-level students who have yet to really discover their passion. 


\section{Conclusion}

This study was an effort to extend the grit construct of Duckworth et al. (2007) to pre-university science students at the two-year college or CEGEP level. This study builds on current research on the grit-like personality trait. Our results showed grit was not a significant predictor of academic achievement in pre-university college-level physics program. These findings appear to be contrary to findings by Duckworth et al. (2007). Our study supports earlier findings that prior academic achievement is the most reliable predictor of student success in college, especially at the two-year college or CEGEP level (Duckworth et al., 2007; Gottfredson, 1997; Hartigan \& Wigdor, 1989; Pascarella \& Terenzini, 2005). As previously documented by Duckworth et al. (2007), more educated adults had higher grit than less educated adults of similar age, and when age is controlled for, postcollege graduates had higher grit than most other groups. Furthermore, their study showed that when education is controlled for, grit increases with age. Consequently, grit may be less effective in predicting academic achievement in a selective program, which may dissuade less motivated and less self-regulated students in the first place. Further, maturational factors may also attenuate the effects of individual trait-like perserverance, which may only become salient in more specialized contexts, among higher performing populations.

This study is limited by its case study design and its use of a convenience sample. Findings cannot be generalized to college-level student populations. We did not examine the relationship between grit scores and student retention in the physics program. More research among different populations employing a greater diversity of measures for triangulation is necessary to further describe the grit construct and to better understand its relationship to other achievement-related measures and the roles they play in student retention and academic success. Future studies should inquire whether gritty people in fact: (a) prioritize long-term stamina over short-term intensity, (b) specify consistent goals and interests over time, and/or (c) set extreme long term goals, and do not swerve. Studies will require mixed-method, longitudinal designs in order to answer these questions.

\section{Acknowledgements}

Include any acknowledgements here.

\section{References}

Batres, I. (2011). The relationship of grit, subjective happiness and meaning in life on alternative education students' GPA and attendance (Order No. 3480016). Available from ProQuest Central; ProQuest Dissertations \& Theses Full Text. (897661487).

Bowman, N., Hill, P., Denson, N., \& Bronkema, R. (2015). Keep on Truckin' or Stay the Course? Exploring Grit Dimensions as Differential Predictors of Educational Achievement, Satisfaction, and Intentions. Social Psychological And Personality Science, 6(6), 639-645. doi:10.1177/1948550615574300

Cabrera, A., Nora, A., Terenzini, P., Pascarella, E., \& Hagedorn, L. (1999). Campus Racial Climate and the Adjustment of Students to College: A Comparison between White Students and African-American Students. The Journal Of Higher Education, 70(2), 134. doi:10.2307/2649125

Chang, W. (2014). Grit and Academic Performance: Is Being Grittier Better? Open Access Dissertations. Paper 1306.

Chen, X. (2013). STEM Attrition: College Students' Paths Into and Out of STEM Fields (NCES 2014-001). National Center for Education Statistics, Institute of Education Sciences, U.S. Department of Education. Washington, DC.

Duckworth, A. L., Peterson, C., Matthews, M. D., \& Kelly, D. R. (2007). Grit: Perseverance and passion for long-term goals. Journal of Personality and Social Psychology, 92(6), 1087-1101. doi:10.1037/0022-3514.92.6.1087

Duckworth, A. L. \& Seligman, M. E. P. (2005). Self-discipline outdoes IQ in predicting academic performance of adolescents. Journal of Educational Psychology, 16(12), 939-944.

Duckworth, A., Kirby, T., Tsukayama, E., Berstein, H., \& Ericsson, K. (2010). Deliberate Practice Spells Success: Why Grittier Competitors Triumph at the National Spelling Bee. Social Psychological And Personality Science, 2(2), 174-181. doi:10.1177/1948550610385872

Duckworth, A., \& Quinn, P. (2009). Development and Validation of the Short Grit Scale (Grit-S). Journal Of Personality Assessment, 91(2), 166-174. doi:10.1080/00223890802634290

De Vera, M. J., Gavino Jr, J. C., \& Portugal, E. J. (2015). Grit and superior work performance in an Asian context. Proceedings of 11th International Business and Social Science Research Conference, January 2015, Crowne Plaza Hotel, Dubai.

Dweck, C. (2007). Mindset: The New Psychology of Success. New York: Ballantine Books.

Ericsson, K. A. (2006). The influence of experience and deliberate practice on the development of superior expert performance. In K. A. Ericsson, N. Charness, P. Feltovich, and R. R. Hoffman (Eds.). Cambridge handbook of expertise and expert performance (pp. 685-706). Cambridge, UK: Cambridge University Press. 
Galla, B. M., Plummer, B. D., White, R. E., Meketon, D., D’Mello, S. K., \& Duckworth, A. L. (2014). The Academic Diligence Task (ADT): assessing individual differences in effort on tedious but important schoolwork. Contemporary Educational Psychology, 39(4), 314-325. http:// doi.org/10.1016/j.cedpsych.2014.08.001

Gasiewski, J., Eagan, M., Garcia, G., Hurtado, S., \& Chang, M. (2011). From Gatekeeping to Engagement: A Multicontextual, Mixed Method Study of Student Academic Engagement in Introductory STEM Courses. Research in Higher Education, 53(2), 229-261. doi:10.1007/s11162-011-9247-y.

Gottfredson, L. S. (1997). Why grit matters: The complexity of everyday life. Intelligence, 24, 79-132.

Hartigan, J., \& Wigdor, A. (1989). Fairness in employment testing: Validity generalization, minority issues, and the general aptitude test battery. Washington, DC: National Academy Press.

Hogan, M., \& Wong, K. (2013). Grit and Mindset: Do you have the Grit to go the distance? Women Lawyers Journal Vol. 98 , No. 3.

Ishitani, T., \& Desjardins, S. (2002). A longitudinal investigation of dropout from college in the United States. Journal Of College Student Retention: Research, Theory And Practice, 4(2), 173-201. doi:10.2190/v4en-nw42-742q-2ntl

Ivcevic, Z., \& Brackett, M. (2014). Predicting school success: Comparing Conscientiousness, Grit, and Emotion Regulation Ability. Journal of Research In Personality, 52, 29-36. doi:10.1016/j.jpp.2014.06.005.

Jaeger, B., Freeman, S., Whalen, R., \& Payne, R. (2010). Successful students: Smart or tough? Paper presented at 2010 Annual Conference and Exposition: Research on the First Year. American Society of Engineering Education.

Komarraju, M., Karau, S., \& Schmeck, R. (2009). Role of the Big Five personality traits in predicting college students' academic motivation and achievement. Learning And Individual Differences, 19(1), 47-52.

Komarraju, M., Ramsey, A., \& Rinella, V. (2013). Cognitive and non-cognitive predictors of college readiness and performance: Role of academic discipline. Learning E Individual Differences, 24, 103-109. doi:10.1016/j.lindif.2012.12.007

Meriac, J. (2013). Examining relationships among work ethic, academic motivation and performance. Educational Psychology, 35(5), 523-540. doi:10.1080/01443410.2014.895291

Moutafi, J., Furnham, A., \& Paltiel, L. (2005). Can personality factors predict intelligence? Personality and Individual Differences, 38(5), 1021-1033.

Meyers, R., Pignault, A., \& Houssemand, C. (2013). The Role of Motivation and Self-regulation in Dropping Out of School. Procedia - Social and Behavioral Sciences, 89(2009), 270-275. http:// doi.org/10.1016/j.sbspro.2013.08.845

Pascarella, E. T., \& Terenzini, P. T. (2005). How college affects students: Vol 2. A third decade of research. San Francisco, CA: Jossey-Bass.

Piña-Watson, B., López, B., Ojeda, L., \& Rodriguez, K. M. (2015). Cultural and Cognitive Predictors of Academic Motivation Among Mexican American Adolescents: Caution Against Discounting the Impact of Cultural Processes. Journal of Multicultural Counseling and Development, 43(2), 109-121. http:/ / doi.org/10.1002/j.2161-1912.2015.00068.x

Poropat, A. (2009). A meta-analysis of the five-factor model of personality and academic performance. Psychological Bulletin, 135(2), 322-338. doi:10.1037/a0014996

Rocher, G. (2008). L'engendrement du cégep par la commission Parent. In L. Héon, D. Savard, \& T. Hamel (Eds.), Les cégeps: une grande aventure collective québécoise (pp. 9-16). Québec: Presses de l'Université Laval (PUL).

Rojas, J. P., Reser, J. A., Usher, E. L., \& Toland, M. D. (2012). Psychometric properties of the academic grit scale. Lexington: University of Kentucky.

Strayhorn, T. (2013). What Role Does Grit Play in the Academic Success of Black Male Collegians at Predominantly White Institutions?. Journal of African American Studies, 18(1), 1-10. doi:10.1007/s12111-012-9243-0

Tversky, A., \& Kahneman, D. (1974). Judgment under Uncertainty: Heuristics and Biases. Science, 185(4157), 1124-1131. http://doi.org/10.1126/science.185.4157.1124 